\title{
Formulasi dan Evaluasi Losion Tabir Surya Ekstrak Daun Stevia (Stevia rebaudiana Bertoni M)
}

\author{
(Formulation and Evaluation of Sunscreen Lotions of Stevia (Stevia rebaudiana Bertoni M)
}

Leaf Extracts)

\section{Yola Desnera Putri*, Haruman Kartamihardja, \& Intan Lisna}

Sekolah Tinggi Farmasi Indonesia, JI. Soekarno-Hatta No.354, Batununggal, Bandung, WJawa Barat 40266, Indonesia

\begin{abstract}
Stevia leaves (Stevia rebaudiana Bertoni M) besides being used as sugar base ingredients also have natural compounds that can be used as sunscreens such as flavonoids and phenolics. Flavonoids in plants has the potential as a sunscreen because it has chromophore which is conjugated aromatic system which causes a strong ability to absorb light at a wavelength range of UV rays, so flavonoids compound can be used as efficacious compounds in sunscreen preparations. The purpose of this study was determined the concentration of stevia leaf extracts which has activity as a sunscreen and made a preparation of sunscreen lotion from extract. The results of the SPF value from stevia leaves extract with a concentration $0.05 \%$ was 15.247 , while the SPF value of sunscreen lotion containing stevia leaves extract 0.05\% for F1 11.052; F2 10.363; F3 10.175; and F4 8.315. The evaluation result from sunscreen lotion had green colours; $\mathrm{pH}$ range 7.21-8.11; viscosity range 2000-8000cps; and the centrifugation test was there was no separation from lotions. All of lotion formulations which containing stevia leaves extract are included in the range of maximum protection sunscreen values.
\end{abstract}

Keywords: stevia Leaves (Stevia rebaudiana Bertoni M); sunscreen; Lotion; SPF.

ABSTRAK: Daun stevia (Stevia rebaudiana Bertoni M) selain digunakan sebagai bahan dasar gula juga memiliki senyawa alami yang dapat digunakan sebagai tabir surya seperti flavonoid dan fenolat. Flavonoid dalam tanaman memiliki potensi sebagai tabir surya karena adanya gugus kromofor, gugus kromofor tersebut merupakan sistem aromatik terkonjugasi yang menyebabkan kemampuan untuk menyerap kuat sinar pada kisaran panjang gelombang sinar UV, sehingga senyawa flavonoid dapat digunakan sebagai senyawa berkhasiat dalam sediaan tabir surya. Tujuan dari penelitian ini yaitu menentukan konsentrasi dari ekstrak daun stevia yang memiliki aktivitas sebagai tabir surya dan membuat sediaan losion tabir surya dari daun stevia. Hasil nilai SPF dari ekstrak etanol daun stevia dengan konsentrasi $0,05 \%$ sebesar 15,247 , sedangkan hasil nilai SPF losion tabir surya yang mengandung ekstrak etanol daun stevia 0,05\% untuk F1 11,052; F2 10,363; F3 10,175; dan F4 8,315. Hasil evaluasi losion tabir surya ini losion memiliki warna hijau, pH losion 7,21-8,11, viskositas losion 2000-8000cps, dan uji sentrifugasi losion tidak terjadi pemisahan. Nilai SPF keempat formulasi losion tersebut termasuk kedalam rentang nilai tabir surya proteksi maksimal.

Kata kunci: daun stevia (Stevia rebaudiana Bertoni M); tabir surya, losion, SPF .

\section{Pendahuluan}

Pemaparan sinar ultraviolet dari matahari secara kronik akan mengakibatkan perubahan struktur dan komposisi kulit dan stress oksidatif pada kulit. Efek yang ditimbulkan dapat berupa perubahan-perubahan akut seperti eritema, pigmentasi dan fotosensitivitas, maupun efek jangka panjang berupa penuaan dini dan keganasan kulit. Sinar UV merupakan sinar matahari yang memiliki komponen kecil dari spektrum elektromagnetik dan memiliki rentang radiasi yang sempit, yaitu pada panjang gelombang 200-400 nm. Spektrum sinar UV dibagi menjadi 3, yaitu UV C (200-290 nm), UV B (290-320 nm), dan UV A (320-400 nm) [1].
Kulit memiliki mekanisme pertahanan terhadap efek toksik dari paparan sinar matahari, seperti pengeluaran keringat, pembentukan melanin dan penebalan sel tanduk. Akan tetapi, pada penyinaran yang berlebih sistem perlindungan tersebut tidak mencukupi karena banyak pengaruh lingkungan yang secara cepat atau lambat dapat merusak jaringan kulit. Oleh karena itu, diperlukan perlindungan kulit tambahan dengan dibuat sediaan kosmetika pelindung kulit, yaitu kosmetika tabir surya. Tabir surya merupakan sediaan kosmetik yang digunakan dengan maksud memantulkan

\section{Article history}

Received: 02 Maret 2019 Accepted: 23 Mei 2019 Published: 30 Mei 2019

Access this article

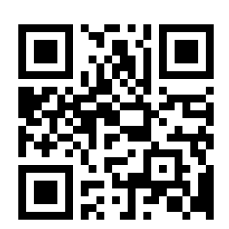


atau menyerap sinar UV sehingga dapat mengurangi jumlah radiasi UV yang berbahaya bagi kulit [2]. Tabir surya dengan zat aktif menggunakan senyawa sintesis dikhawatirkan menimbulkan efek samping pada kulit manusia, sehingga beberapa tahun terakhir ini telah banyak peneliti mengklaim bahwa kosmetik yang mengandung komponen senyawa herbal lebih aman untuk kulit hiperalergi. Hal tersebut dikarenakan bahan alam memiliki potensi kecil dalam menimbulkan iritasi dan lebih mudah cocok pada kulit. Selain itu, tabir surya dengan bahan alami lebih toleran terhadap kulit manusia [3].

Tanaman stevia (Stevia rebaudiana Bertoni M.) diketahui mempunyai beberapa manfaat dalam bidang farmasi dan digunakan sebagai terapi karena berfungsi sebagai antioksidan, antijamur, dan non karsinogenik [4]. Selain itu, stevia memiliki kandungan metabolit lain yang memiliki potensial bioaktif, alkaloid, klorofil yang larut dalam air, xantofil, asam amino, lemak, flavonoid, senyawa fenol, tanin, dan asam askorbat [5]. Beberapa senyawa aktif seperti flavonoid, fenolat, tannin, antraquinon, sinamat, kurkumin, dan lain-lain telah dilaporkan memiliki kemampuan sebagai pelindung terhadap sinar UV [6].

Flavonoid memiliki potensi sebagai tabir surya karena adanya gugus kromofor yang umumnya memberi warna pada tanaman. Gugus kromofor tersebut merupakan sistem aromatik terkonjugasi yang menyebabkan kemampuan untuk menyerap kuat sinar pada kisaran panjang gelombang sinar UV [7].

Pada penelitian sebelumnya, banyak peneliti yang meneliti tentang kandungan antioksidan dan kandungan total senyawa fenol yang terdapat dalam ekstrak daun stevia. Menurut Ismet dkk (2010), ekstrak etanol dari maserasi daun stevia memiliki nilai total fenol, nilai total flavonoid, dan aktivitas antioksidannya lebih besar dibandingkan dengan proses ekstraksi soxhlet. Pada ekstraksi daun stevia menggunakan maserasi memiliki nilai total fenol sebesar $65,21 \mathrm{mg}$ asam galat yang ekuivalen dengan senyawa fenol dan pada pengujian antioksidan ekstrak daun stevia memiliki nilai IC50 sebesar 8,02 ppm. Selain itu, ekstrak etanol daun stevia memiliki nilai sebesar 125,64 mg quersetin yang ekuivalen dengan senyawa flavonoid. Adanya kandungan flavonoid didalam daun stevia ini memungkinkan daun stevia memiliki aktivitas sebagai tabir surya [8].

Bentuk sediaan tabir surya yang banyak beredar dipasaran berupa losion. Lotion menurut The British Pharmacentical Codex adalah sediaan cair ditujukan untuk aplikasi ke kulit, atau menggunakan bulu sebagai mencuci untuk irigasi aural, hidung, mata, lisan, atau uretra. Biasanya mengandung zat kimia tertentu dalam suspensi atau larutan di dalam pembawa air. Losion juga lebih mudah digunakan pada kulit karena konsistensinya yang tidak terlalu padat, sehingga dapat menyebar lebih merata dan cepat pada permukaan kulit yang luas. Penggunaan losion juga cepat kering setelah pemakaian dan meninggalkan lapisan tipis dari komponen obat pada permukaan kulit [9].

Berdasarkan uraian diatas maka perlu dilakukan penelitian untuk mengetahui aktivitas dan stabilitas tabir surya dari ekstrak daun stevia yang akan dibuat sediaan losion tabir surya.

\section{Metode Penelitian}

Bahan

Daun stevia (Stevia rebaudiana Bertoni M.) (Solo, Indonesia), setil alkohol (Pharma Lab, Indonesia), asam sterat (Pharma Lab, Indonesia), gliserin (Petronas Chemical, Indonesia), trietanolamin (Petronas Chemical, Indonesia), metilparaben (UENO Japan), propilparaben (Rasula India) dan akuades (Brataco, Indonesia).

\section{Ekstraksi Maserasi}

Serbuk simplisia daun stevia ditimbang sebanyak 100 gram dimaserasi menggunakan pelarut etanol 96\% (1 L). Penggantian pelarut dalam suhu kamar dilakukan setiap 24 jam sebanyak 3 kali. Maserat kemudian dikentalkan sampai mendapatkan ektrak kental.

Penentuan SPF Ekstrak Secara Invitro [10]

Penentuan efektivitas tabir surya dilakukan dengan menentukan nilai SPF secara in vitro dengan spektrofotometer UV-Vis (Shimadzu UV-1800®). Ekstrak diencerkan dengan konsentrasi 100 ppm, 200 ppm, 300 ppm, 400 ppm, dan 500 ppm. Dibuat kurva serapan uji dalam kuvet, dengan panjang gelombang antara 290-320 $\mathrm{nm}$ dan dihitung nilai SPF nya. Rumus penghitungan SPF yang digunakan :

\section{$\mathrm{SPF}=\mathrm{CF} \times \sum_{290}^{320} E E(\lambda) \times I(\lambda) x$ absorbansi $(\lambda)$}

\author{
Keterangan : \\ $\mathrm{CF}=$ Faktor kolerasi (10) \\ $\mathrm{EE}=$ Eritemal effect spectrum \\ I $\quad=$ Spektrum simulasi sinar surya \\ Abs $\quad=$ Absorbansi produk tabir surya
}

\section{Formulasi Losion Ekstrak Daun Stevia}

Formula losion dapat dilihat pada tabel 1. Bahanbahan yang digunakan dipisah menjadi dua bagian, yaitu bahan yang larut fase minyak dan bahan yang larut fase air. Bahan-bahan yang larut minyak yaitu asam stearat, setil alkohol, nipasol, dan parafin cair dimasukkan ke dalam cawan penguap dan dipanaskan pada suhu $70^{\circ} \mathrm{C}$. Bahan- 
Tabel 1. Formulasi Losion Ekstrak Daun Stevia

\begin{tabular}{ccccc}
\hline \multirow{2}{*}{ Bahan } & \multicolumn{3}{c}{ Kadar (gram) } \\
\cline { 2 - 5 } & F.1 & F.2 & F.3 & F.4 \\
\hline $\begin{array}{c}\text { Ekstrak daun } \\
\text { Stevia } \\
\text { Setil alkohol }\end{array}$ & 0,5 & 0,5 & 0,5 & 0,5 \\
Paraffin cair & 0,5 & 0,5 & 0,5 & 0,5 \\
Asam sterat & 7,0 & 7,0 & 7,0 & 7,0 \\
Gliserin & 2,5 & 5,0 & 7,5 & 10 \\
Trietanolamin & 5,0 & 5,0 & 5,0 & 5,0 \\
Nipagin & 1,0 & 1,0 & 1,0 & 1,0 \\
Nipasol & 0,1 & 0,1 & 0,1 & 0,1 \\
Akuades & 0,1 & 0,1 & 0,1 & 0,1 \\
& Ad & Ad & Ad & Ad \\
\hline
\end{tabular}

bahan yang larut air yaitu trietanolamin, nipagin, dan gliserin dilarutkan dengan akuades dengan pengadukan. Kemudian, fase minyak dicampurkan dalam fase larut air pada suhu $70{ }^{\circ} \mathrm{C}$ dengan dilakukan pengadukan hingga homogen. Pengadukan hingga homogen dilakukan sampai suhu losion menjadi $15{ }^{\circ} \mathrm{C}-30{ }^{\circ} \mathrm{C}$. Kemudian ekstrak stevia ditambahkan pada losion dan aduk kembali hingga homogen.

Evaluasi Sediaan Losion Tabir Surya

Evaluasi sediaan losion meliputi pengamatan organoleptis (warna, bau, bentuk, homogenitas), $\mathrm{pH}$, viskositas, uji kestabilan fisik losion, penentuan SPF ekstrak dan sediaan, dan penentuan tipe losion. Pengamatan $\mathrm{pH}$ sediaan losion dilakukan menggunakan alat $\mathrm{pH}$ meter (Mettler Toledo $\left.{ }^{\circledR}\right)$. Sebelum digunakan, alat $\mathrm{pH}$ meter dikalibrasi menggunakan buffer $\mathrm{pH} 4.0 \mathrm{pH} 7.0$ dan $\mathrm{pH}$ 9.0. Pengujian dilakukan dengan mencelupkan elektroda ke dalam sediaan losion, lalu ditunggu sampai angka yang muncul pada layar stabil. Pengamatan viskositas dilakukan selama 1 bulan pada minggu I sampai dengan minggu ke IV. Viskositas tersebut diuji menggunakan Viskometer Brookfield DV-E dengan spindle No.4 dan kecepatan 6 rpm. 4. Pengujian Kestabilan Fisik Losion, sebanyak 2 gram dimasukan kedalam tabung sentrifus lalu disentrifugasi pada kecepatan $5000 \mathrm{rpm}$ selama 10 menit. Setelah disentrifugasi losion diamati apakah terjadi pemisahan atau tidak pada fase minyak dan fase air. Pengujian tipe losion menggunakan metilen biru, pada losion diteteskan metilen biru. Apabila metilen biru dan losion tidak bercampur, berarti losion tipe w/o, tetapi jika metilen biru dan losion bercampur berati losion tersebut tipe o/w.

\section{Hasil dan Diskusi}

Hasil pengamatan organoleptis selama 28 hari meliputi bentuk, warna dan bau losion selama penyimpanan, dari keempat formulasi yang dibuat baik bentuk, warna dan bau sediaan losion yang dihasilkan tidak mengalami perubahan perubahan. Hal ini menunjukkan bahwa keempat losion tersebut stabil secara fisik. Hasil pengamatan organoleptis dapat dilihat pada tabel 2.

Hasil penentuan SPF tercantum dalam tabel 3 , terlihat bahwa ekstrak etanol daun stevia dengan konsentrasi 500 ppm $(0,05 \%)$ memiliki nilai SPF rata-rata yaitu 15,247 dan termasuk kedalam tabir surya yang memiliki proteksi maksimal menurut Food and Drug Administration (FDA), dari data tersebut diketahui bahwa ekstrak etanol daun stevia dapat dijadikan suatu sediaan tabir surya. Persamaan regresinya adalah $y=3,1159 . x+1,1083$ sehingga dapat dihitung konsentrasi yang dibutuhkan untuk membuat losion tabir surya yang diinginkan untuk formula sediaan losion tabir surya. Konsentrasi yang diambil untuk dimasukan kedalam formula yaitu $50 \mathrm{mg}$ dengan nilai SPF 15 pada masing-masing formula losion.

Namun beberapa penelitian untuk pembuatan tabir surya sebelumnya menyatakan bahwa nilai SPF pada suatu sediaan tabir surya menggunakan ekstrak akan menurun setelah ekstrak ditambahkan kedalam formula, maka dari itu pada penelitian ini ekstrak yang dimasukan kedalam formula 10 kali lipat dari hasil perhitungan regresi linear 
yaitu 0,5 gram agar mencapai SPF standar untuk sediaan tabir surya.

Selanjutnya dilakukan evaluasi $\mathrm{pH}$ pada sediaan losion, evaluasi $\mathrm{pH}$ ini bertujuan untuk mengetahui losion yang dihasilkan memiliki $\mathrm{pH}$ yang sesuai dengan $\mathrm{pH}$ kulit. $\mathrm{pH}$ yang dihasilkan dari keempat formula berada diantara 7,21-8,11, akan tetapi menurut jika kulit yang memiliki $\mathrm{pH}$ 5,0-6,5 dapat beradaptasi dengan baik saat berinteraksi dengan bahan yang memiliki $\mathrm{pH}$ 4,5-8,0 [11].

Pengukuran viskositas pada basis losion dan sediaan losion untuk ke-4 formula losion yaitu formula 1, 2, 3, dan 4 menghasilkan nilai viskositas yang berbeda. Dimana terjadi penurunan nilai viskositas dari ke-4 basis losion setelah dibuat menjadi sediaan losion, akan tetapi nilai viskositas yang dihasilkan dari keempat sediaan losion tidak melebihi nilai viskositas yang dipersyaratkan untuk sediaan tabir surya yaitu 2000-50.000 cPs (SNI,1996). Pada penelitian ini terjadinya penurunan viskositas yang dapat disebabkan oleh beberapa hal antara lain faktor pencampuran atau pengadukan saat membuat emulsi, konsentrasi zat pengental [12].

Pengujian stabilitas losion meliputi uji sentrifugasi, parameter dari kedua pengujian tersebut yaitu tidak terjadi pemisahan fase pada sediaan losion. Pengujian sentrifugasi ini dilakukan untuk mengetahui terjadi pemisahan fase atau tidak pada sediaan losion yang dibuat. Pengujian ini diperlukan untuk mengetahui efek guncangan pada saat transport produk terhadap tampilan fisik produk. Pada sediaan losion baik formula 1, 2, 3,dan 4 setelah dilakukan pengujian tersebut tidak ada satupun formula losion yang menunjukkan terjadi pemisahan fase [13].

Hasil dari pengujian tipe losion tabir surya dari ekstrak daun stevia memiliki tipe losion $\mathrm{m} / \mathrm{a}$. Tipe losion $\mathrm{m} / \mathrm{a}$ lebih cepat meresap pada kulit dan tidak meninggalkan rasa lengket saat digunakan, selain itu tipe losion ini penyebarannya lebih merata pada kulit [14].

Losion tabir surya dengan konsentrasi ekstrak daun stevia $0,05 \%$ pada formula ke-1 memiliki nilai SPF 11, 052, formula ke-2 memiliki nilai SPF 10,363, formula ke-3 memiliki nilai SPF 10,175, dan formula ke-4 memiliki nilai SPF 8,315 (tabel 4). Dari ke empat formula tersebut semuanya termasuk kedalam rentang nilai tabir surya proteksi maksimal (nilai SPF $8 \mathrm{~s} / \mathrm{d}<15$ ) (Food and Drug Administration) [15].

Tabel 2. Pengamatan Organoleptis Losion

\begin{tabular}{|c|c|c|c|c|c|c|}
\hline \multirow{2}{*}{ Bahan } & \multirow{2}{*}{ Sediaan } & \multicolumn{5}{|c|}{ Lama Pengamatan } \\
\hline & & 1 & 7 & 14 & 21 & 28 \\
\hline \multirow[t]{4}{*}{ Warna } & $\mathrm{F} 1$ & $\mathrm{Hm}$ & $\mathrm{Hm}$ & $\mathrm{Hm}$ & $\mathrm{Hm}$ & $\mathrm{Hm}$ \\
\hline & $\mathrm{F} 2$ & $\mathrm{Hm}$ & $\mathrm{Hm}$ & $\mathrm{Hm}$ & $\mathrm{Hm}$ & $\mathrm{Hm}$ \\
\hline & F3 & $\mathrm{Hm}$ & $\mathrm{Hm}$ & $\mathrm{Hm}$ & $\mathrm{Hm}$ & $\mathrm{Hm}$ \\
\hline & $\mathrm{F} 4$ & $\mathrm{Hm}$ & $\mathrm{Hm}$ & $\mathrm{Hm}$ & $\mathrm{Hm}$ & $\mathrm{Hm}$ \\
\hline \multirow[t]{4}{*}{ Bentuk } & $\mathrm{F} 1$ & K & $\mathrm{K}$ & K & K & K \\
\hline & $\mathrm{F} 2$ & K & K & K & K & $\mathrm{K}$ \\
\hline & F3 & $\mathrm{K}$ & $\mathrm{K}$ & K & $\mathrm{K}$ & $\mathrm{K}$ \\
\hline & $\mathrm{F} 4$ & K & $\mathrm{K}$ & $\mathrm{K}$ & K & $\mathrm{K}$ \\
\hline \multirow[t]{4}{*}{ Bau } & $\mathrm{F} 1$ & $\mathrm{Bk}$ & $\mathrm{Bk}$ & $\mathrm{Bk}$ & Bk & $B k$ \\
\hline & $\mathrm{F} 2$ & $\mathrm{Bk}$ & $\mathrm{Bk}$ & $\mathrm{Bk}$ & Bk & $\mathrm{Bk}$ \\
\hline & F3 & $\mathrm{Bk}$ & $\mathrm{Bk}$ & Bk & Bk & $\mathrm{Bk}$ \\
\hline & F4 & $\mathrm{Bk}$ & Bk & $\mathrm{Bk}$ & $\mathrm{Bk}$ & Bk \\
\hline
\end{tabular}

keterangan :

$\begin{array}{llll}\text { F1 } & \text { : Formula } 1 & \text { Hm } & \text { : Hijau muda } \\ \text { F2 } & \text { : Formula } 2 & \mathrm{~K} & \text { : Kental } \\ \text { F3 } & \text { : Formula 3 } & \text { BK } & \text { : Bau Khas } \\ \text { F4 } & \text { : Formula } 4 & & \end{array}$


Tabel 3. Nilai SPF Ekstrak Daun Stevia

\begin{tabular}{cc}
\hline Sediaan & $\begin{array}{c}\text { Nilai Sun Protection Factor (SPF) } \\
\text { Extrack Daun Stevia (0,05\% b/v) }\end{array}$ \\
\hline 1. & 15,249 \\
2. & 15,247 \\
3. & 15,245 \\
Rata-rata & 15,247 \\
Simpangan baku & 0,002 \\
\hline
\end{tabular}

Tabel 4. Nilai SPF Ekstrak Daun Stevia

\begin{tabular}{cc}
\hline Sediaan & $\begin{array}{c}\text { Nilai Sun Protection Factor (SPF) } \\
\text { Lotion Daun Stevia (0,05\% b/v) }\end{array}$ \\
\hline F1 & 11,052 \\
F2 & 10,363 \\
F3 & 10,175 \\
F4 & 8,315 \\
\hline
\end{tabular}

Dari data formulasi tersebut maka dapat diketahui bahwa dari ke empat formula tersebut termasuk kedalam rentang kategori tabir surya maksimal. Hal ini menunjukkan bahwa losion ekstrak etanol dari daun stevia memiliki potensi kemampuan tabir surya yang baik.

Nilai SPF dari sediaan losion lebih kecil dibandingkan dengan nilai SPF pada ekstrak hal ini dikarenakan dapat dipengaruhi oleh kombinasi dan konsentrasi dari losion tabir surya, tipe losion, efek dan interaksi dari komponen pembawa misalnya emollient yang digunakan pada formulasi. Faktor ini dapat menambah atau mengurangi penyerapan UV pada tabir surya [16].

\section{Kesimpulan}

SPF dari ekstrak etanol daun stevia pada konsentrasi $0,05 \%$ yaitu 15,247. Nilai SPF dari sediaan losion formula $1,2,3$, dan 4 yang mengandung ekstrak etanol daun stevia sebesar 0,05\% memiliki nilai SPF 11,052; 10,363; 10,175; 8,315. Nilai SPF dari keempat losion tersebut termasuk kedalam rentang nilai tabir surya proteksi maksimal.

\section{Referensi}

[1] Matts, Paul J. Solar ultraviolet radiation: definitions and terminology Dermatologic clinics; 2006, 24.1: 1-8.

[2] Draelos, Zoe Diana. Cosmetic formulation of skin care products. In: Cosmetic Formulation of Skin Care Products. CRC Press; 2006. p. 456.

[3] Cefali, L. C., Ataide, J. A., Moriel, P., Foglio, M. A., \& Mazzola, P. G. Plant-based active photoprotectants for sunscreens. International journal of cosmetic science; 2016. 38.4: 346-353.

4] Gupta, E., Purwar, S., Sundaram, S., \& Rai, G. K. Nutritional and therapeutic values of Stevia rebaudiana: A review. Journal of Medicinal Plants Research; 2013. 7(46), 3343-3353.

[5] Barroso, M., Barros, L., Rodrigues, M. Â., Sousa, M. J., SantosBuelga, C., \& Ferreira, I. C. Stevia rebaudiana Bertoni cultivated in Portugal: A prospective study of its antioxidant potential in different conservation conditions. Industrial Crops and Products; 2016. 90 49-55.

[6] Maheshwar, G. H., Patil, B. S., \& Dhumal, P. Comparative sun protection factor determination of fresh fruits extract of Cucumber vs marketed cosmetic formulation. Research Journal of Pharmaceutical Biological and Chemical Sciences; 2010. 1(3), 55-59.

[7] Prasiddha, I. J., Laeilocattleya, R. A., Estiasih, T., \& Maligan, J. M. Potensi senyawa bioaktif rambut jagung (Zea mays L.) untuk tabir surya alami. Jurnal pangan dan agroindustri; 2015, 4(1).

[8] Jahan, I. A., Mostafa, M., Hossain, H., Nimmi, I., Sattar, A., Alim, A., \& Moeiz, S. M. I. Antioxidant activity of Stevia rebaudiana Bert. leaves from Bangladesh. Bangladesh Pharm. J; 2010, 13(2), 67-75.

[9] Ansel, H.C. Bentuk Sediaan Farmasetis \& Sistem Penghantaran Obat. Edisi Sembilan. Jakarta: EGC. 2013. Hal. 291

[10] Ismet, A., Mohammad, M., Hemayet, H., Ishrat, N., Abdus, S., Abdul, A., Syed, M. 2010. "Antioxidant activity of Stevia rebaudiana Bert. Leaves from Bangladesh". Bangladesh Pharmaceutical Journal 13(2): 67-75.

[11] Standar Nasional Indonesia 164399. Sediaan Tabir Surya. Jakarta Badan Standarisasi Nasional. 1996.

[12] Anita, Syeni Budi. Aplikasi karaginan dalam pembuatan skin lotion [skripsi]. Bogor: Institut Pertanian Bogor, 2008.

[13] Putri, Nabila. S., Mulyanti, D., dan Gadri, A., Formulasi Sediaan Krim Tabir Surya Ekstrak Teh Putih (Camellia Sinensis L. Ok). 2015.

[14] Nonci, F. Y., Tahar, N., \& Aini, Q. Formulasi dan Uji Stabilitas Fisik Krim Susu Kuda Sumbawa dengan Emulgator Nonionik dan Anionik. Jurnal Farmasi UIN Alauddin Makassar, 2017. 4(4), 169-178.

[15] Cefali, L.C., Ataide, J.A., Moriel, P., Foglio, M.A., and Mazzola, P.A 2016. "Plant Compounds as Active Photo Protectants in Sunscreen". International Journal of Cosmetic Science : 1-8.

[16] More, B. H., Sakharwade, S. N., Tembhurne, S. V., \& Sakarkar, D. M. Evaluation of Sunscreen activity of Cream containing Leaves Extract of Butea monosperma for Topical application. International Journal of Research in Cosmetic Science, 3(1), 1-6. 2013. 